\title{
Mechanisms of oxidant-induced changes in erythrocytes
}

\author{
J. R. Hatherill ${ }^{1}$, G. O. Till ${ }^{2}$ and P.A. Ward ${ }^{2}$ \\ 1 Radian Corporation, 2250 E. Imperial Hwy., Suite 140, El Segundo, CA 90245, USA \\ 2 Department of Pathology, University of Michigan Medical School, Ann Arbor, MI, USA
}

\begin{abstract}
There is an increasing body of experimental studies demonstrating the toxic effects of oxygen-derived free radicals. Evidence supports an important role for free radicals in ischemic injuries, inflammation, and chemical-induced tissue injury. Free radicals are involved in normal biochemical processes like oxidative reduction and cellular metabolism; however, they also mediate disease processes. The participation of oxygen free radicals in lysis of red cells is important in some situations of intravascular hemolysis. This article will review neutrophil-derived oxygen free radicals, emphasizing: (1) their effects on the erythrocyte and (2) how these effects may be attenuated.
\end{abstract}

\section{Neutrophil-derived oxygen free radical generation}

Many substances are capable of activating neutrophils to release reactive oxygen products, including bacteria and their constitutive components, the membrane activator phorbol myristate acetate (PMA), opsonized zymosan, immune complexes, chemotactic peptides derived from complement components, and synthetic oligopeptides such as $\mathbf{N}$-formyl-methionyl-leucyl-phenylalanine $[1-7]$.

When the neutrophil is activated, a series of metabolic activities is stimulated. Collectively, these changes are termed the "respiratory burst." The respiratory burst is associated with increased oxygen uptake, NADPH production from the hexose monophosphate shunt, and the reduction of oxygen, forming superoxide anion $\left(\mathrm{O}_{2}^{-}\right)$and $\mathrm{H}_{2} \mathrm{O}_{2}$. The majority of oxygen consumed by the leukocytes is converted into superoxide anion or reactive

Supported in part by NIH Grants HL-31963, GM-28499, and GM-29507.

1 Author for correspondence. oxygen products $[6,8]$. Molecular oxygen taken up by the leukocyte is univalently reduced to $\mathrm{H}_{2} \mathrm{O}$.

$$
\mathrm{O}_{2} \stackrel{e^{-}}{\rightarrow} \mathrm{O}_{2}^{-} \stackrel{\mathrm{e}-}{\rightarrow} \mathrm{H}_{2} \mathrm{O}_{2} \stackrel{\mathrm{e}-}{\rightarrow} \cdot \mathrm{OH} \stackrel{\mathrm{e}-}{\rightarrow} \mathrm{H}_{2} \mathrm{O}
$$

The intermediate products, superoxide anions, hydrogen peroxide, and hydroxyl radicals of this pathway are reactive in biological systems to varying degrees $[9,10]$. The formation of $\mathrm{O}_{2}^{-}$results from a membrane-bound NADPH oxidase. Since NADPH oxidase is a surface-bound enzyme, a proportion of $\mathrm{O}_{2}^{-}$diffuses into the extracellular space [5]. Molecules of $\mathrm{O}_{2}^{-}$are capable of forming $\mathrm{H}_{2} \mathrm{O}_{2}$ and oxygen by the dismutation reaction. However, the spontaneous rate of dismutation is very slow in biological systems [9]. Superoxide dismutase (SOD) catalyzes the reaction and is deemed responsible for the majority of $\mathrm{H}_{2} \mathrm{O}_{2}$ evolved by the leukocyte [11]. The hydroxyl radical is postulated to form from the modified Haber-Weiss or Fenton reaction where a transition metal (iron) serves as a redox agent [11].

$$
\begin{gathered}
\mathrm{O}_{2}^{-}+\mathrm{Fe}^{3+} \rightarrow \mathrm{O}_{2} \rightarrow \mathrm{Fe}^{2+} \\
\mathrm{Fe}^{2+}+\mathrm{H}_{2} \mathrm{O}_{2} \rightarrow \mathrm{Fe}^{3+}+\mathrm{OH}^{-}+\cdot \mathrm{OH}
\end{gathered}
$$


Other reactive oxygen species have been postulated or identified to exist. An important species is hypochlorous acid ( $\mathrm{HOCl}$ ), formed by the oxidation of $\mathrm{Cl}^{-}$via the leukocyte myeloperoxidase $\mathrm{H}_{2} \mathrm{O}_{2}$ complex [12].

The formation of toxic oxygen-derived free radicals by leukocytes is an important quality required for host defense against infection. The ability of leukocytes to produce $\mathrm{O}_{2}^{-}$is necessary for destroying some types of bacteria. Chronic granulomatous disease is associated with the inability of phagocytic cells to exhibit the respiratory burst [8].

Free radicals are defined as molecules or atoms with one unpaired electron occupying an outer orbital [10]. Some free radicals in the presence of oxygen can degrade lipids by peroxidative injury [13]. Free radical initiators are capable of extracting hydrogen atoms from unsaturated fatty acids, generating a free radical. This results in electronic instabilities and rearrangement of existing bonds resulting in the formation of conjugated dienes [13]. This may be followed by the addition of oxygen to the diene to form the fatty acid peroxyl radical which can be converted into a lipid endoperoxide. A postulated sequence of events with a polyunsaturated fatty acid (PUFA) is shown in
Fig. 1. Additionally, the peroxyl radical can react with another unsaturated fatty acid producing a lipid hydroperoxide and other alkyl radicals. Alternatively, the result may be the formation of malonaldehyde, malondialdehyde (MDA), conjugated dienes, or Schiff bases can result from the reaction of MDA with amino acids and their esters [13-15].

MDA reacts with free amino groups from nucleic acids, proteins, phospholipids, and amino acids. The reactivity of MDA may result in cross linking and intermolecular bridging $[14,16]$. Furthermore, the conjugated Schiff base $\mathrm{N}, \mathrm{N}^{\prime}$-amino iminopropene can be formed which has a characteristic fluorescent emission range of $440-470 \mathrm{~nm}$ when excited at $360 \mathrm{~nm}[14,16,17]$. These fluorescent pigments were demonstrated to be very similar to lipofuscin, which has been extracted from different animal tissues [17]. Furthermore, toxic 2-alkenals and 4-hydroxyl-2-alkenals can be elaborated by oxygen-derived radical attack upon polyunsaturated fatty acids (PUFA) [18-20]. In addition, oxygen radicals are capable of degrading numerous macromolecules including hyaluronic acid, collagen, inactivating enzymes, mediating the aggregation of gamma globulin, and causing oxidative inactivation of proteins including anti-

\section{STEPS IN LIPID PEROXIDATION}

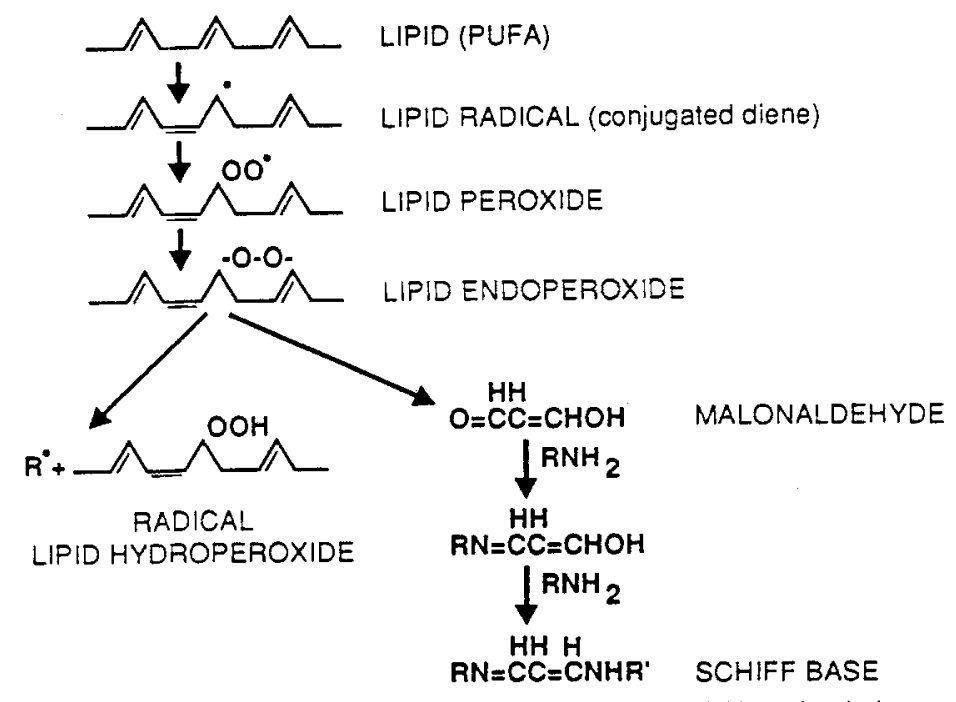

Figure 1

$\mathrm{RN}=\mathrm{CC}=\mathrm{CNHR}$

The pathway for formation of lipid peroxidation products.

(NN'-amino-imino propene) 
proteases [21-28]. There are also numerous studies demonstrating the cytotoxic range of oxygen radicals originating from activated phagocytes. Investigation has shown direct cytotoxic effects from oxygen radicals upon erythrocytes, endothelial cells, fibroblasts, tumor cells, platelets, and spermatozoa [29-38].

\section{Mechanism of oxygen-free radical mediated erythrocyte toxicity}

The participation of oxygen radical species in hemolytic states has been suggested for some time $[39,40]$. In various hemolytic phenomena, the role of oxygen radicals has been suggested [41, 42]. Erythrocyte lysis may be the end result of minor defects in the red blood cell (RBC) membrane. The structural integrity of the membrane is an important feature for its resistance to peroxidative attack [43]. Erythrocytes are also susceptible to oxidative stress due to unsaturated membrane phospholipids [44], continued exposure to high oxygen tension, and a plethora of transition metals capable of serving as redox agents [45, 46]. The presence of hemoglobin and other hematin compounds may also augment the process of lipid peroxidation [47]. When an oxidizing stress overwhelms the reductive process of the red blood cell, a defect may ultimately result in hemolysis due to the inability of $\mathrm{RBCs}$ to resynthesize damaged components [45, 48]. The destruction of red cells is postulated to occur by either membrane oxidation or hemoglobin denaturation.

During oxidant injury, the erythrocyte membrane is stripped of phosphatidylethanolamine (PE) before the cells begin to hemolyze [49]. PE contains a significant amount of polyunsaturated fatty acids which are susceptible to lipid peroxidation [50]. PE can be regenerated by transfer of fatty acids from a neutral lipid pool through phosphatidylcholine to PE [49]. Lubin et al. have demonstrated increased acid transfer during peroxidant injury. However, peroxidation destroys the fatty acids of PE at a faster rate than that of transfer, and hemolysis still occurs. The degradation of PE may also alter the structural relationship of the intgral membrane protein, spectrin, and result in hemolysis [51].

Stimulated neutrophils release reactive oxygen species capable of causing red cell membrane damage to intact cells and erythrocyte ghosts $[31,52$,
53]. Peroxidative injury may directly alter sulfhydryl groups of spectrin by forming disulfide bridges [51]. In addition, there is evidence that altered hemoglobin becomes attached to the inner layer of the red cell membrane via disulfide linkages [54]. Stimulated neutrophils also increase membrane-bound hemoglobin and methemoglobin and promote RBC immunoglobin binding to membranes [55]. MDA is also capable of cross linking free amino groups in the membrane. These linkages promote membrane rigidity and increase the splenic entrapment of $\mathrm{RBC}[49,56,57]$. Hemoglobin alterations may be reflected in globin chain amino acid substitutions. The substitutions may change the physical and chemical properties of the heme pocket such that its iron can facilitate the formation of oxygen radicals $[48,58]$.

Furthermore, RBC membrane-bound enzymes, such as $\mathrm{Na}^{+} / \mathrm{K}^{+}$ATPase, are affected by carbonyl containing substances liberated from oxidized phospholipids [59]. The inhibition of $\mathrm{Na}^{+} / \mathrm{K}^{+} \mathrm{AT}$ Pase may also be related to degradation of phosphatidylserine which is associated with this enzyme [60]. Inhibition of $\mathrm{Na}^{+} / \mathrm{K}^{+}$ATPase will result in increased osmotic fragility. Goldstein demonstrated that exposure of RBC to ozone resulted in increased osmotic fragility associated with production of MDA [6]. It was also demonstrated that $\mathrm{H}_{2} \mathrm{O}_{2}$ stimulates replacement of membrane fatty acids with isotopically labeled fatty acids [6]. In addition, $\mathrm{H}_{2} \mathrm{O}_{2}$ can react with human $\mathrm{RBC}$ causing a cross linking of spectrin to hemoglobin [61]. During oxidizing conditions, the presence of superoxide dismutase, catalase, and radical scavengers can provide protection against red cell lysis [30].

\section{Attenuation of intravascular hemolysis by neutrophil-derived toxic oxygen products}

Recently, we demonstrated that remote thermal trauma to the skin of rats consistently results in intravascular hemolysis and the hemolytic process can be dramatically reduced by antioxidant interventions [62]. We probed into the membrane characteristics of red cells isolated from thermally injured animals. Thin layer chromatography and gel electrophoretic examination of membrane proteins failed to demonstrate significant alterations. Similarly, assays for fluorescent products, MDA, and diene conjugates from erythrocyte 
ghost extracts consistently failed to show evidence for the presence of these products (data not shown). These findings are in accord with other investigators who repeatedly failed to isolate MDA in freshly drawn human blood when subjected to exogenous oxidative stresses [45]. The inability to detect MDA in vivo may result from reactive carbonyl groups which can cross link with a variety of macromolecules $[63,64]$ as previously discussed. Although experiments in vivo have failed to provide evidence for the presence of MDA, red cells exposed to hydrogen peroxide under in vitro conditions demonstrate MDA and its derivatives [50]. As discussed previously, altered hemoglobin can bind internally to red cell membranes [54] and external oxidizing conditions can lead to linkage of surface membrane sulfhydryl groups [51]. Both of these defects result in increased red cell membrane rigidity and possible splenic entrapment [56]. Thus, defective red cells could be sequestered in the sinusoids of the spleen eliminating them from circulation before detectable levels of lipid peroxidation products could accumulate.

Intact human and feline erythrocytes incubated in the presence of activated neutrophils show production of methemoglobin $[65,66]$. It has been postu- lated that oxidized hemoglobin resulted from the diffusion of $\mathrm{O}_{2}^{-}$via $\mathrm{RBC}$ membrane anion channels while $\mathrm{H}_{2} \mathrm{O}_{2}$ appears to be freely diffusible across cell membranes. Our previous studies consistently failed to detect significant levels of methemoglobin in RBC from thermally injured rats. This is not surprising due to the relatively high activity of rat methemoglobin reductase as compared to humans $[67,68]$.

It has been established that thermal injury activates the complement system; however, the precise mechanism is unknown [69]. Complement activation can produce $\mathrm{RBC}$ lysis associated with the C5b-9 membrane attack complex or, indirectly, by the opsonization of $\mathrm{RBC}$ following uptake of $\mathrm{C} 3 \mathrm{~b}$ on surfaces of RBC [69-73]. In our studies, red cells isolated from thermally injured rats did not demonstrate complement uptake; however, it is possible that there were small quantities which were insensitive to detection [62]. Our studies further demonstrated that depletion of either complement or circulating neutrophils precluded the onset of intravascular hemolysis after acute thermal injury [62] (Fig. 2). The depletion of circulating neutrophils prior to thermal trauma reduced by $92.5 \%$ the amount of hemolysis as compared to PMN-sufficient animals. Circulating neutrophils

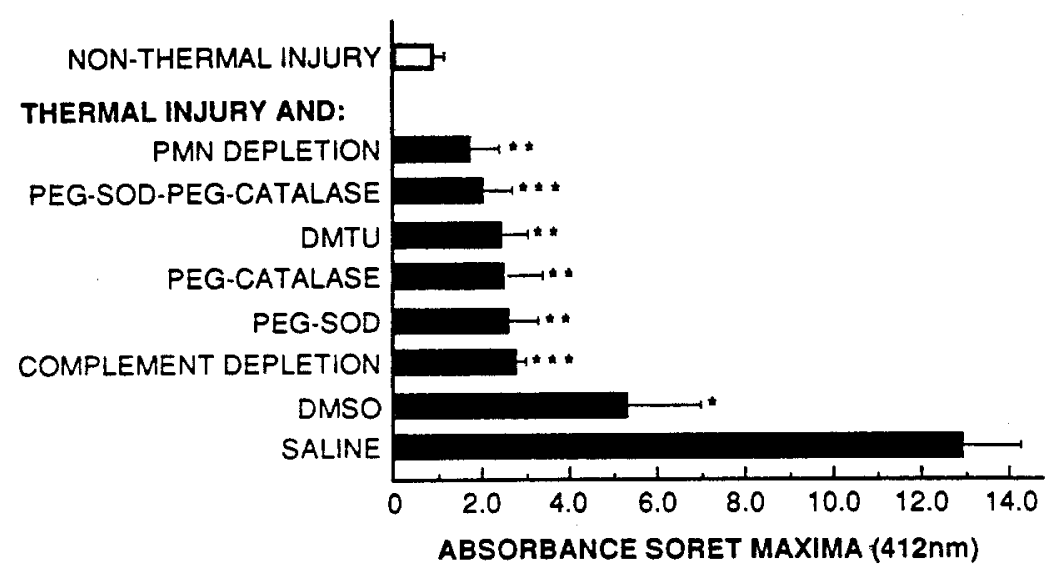

Figure 2

ABSORBANCE SORET MAXIMA (412nm)

Effect of protective interventions on intravascular hemolysis in thermally injured rats at 15 minutes after thermal injury. Animals were pretreated 10 minutes prior to thermal injury with polyethylene glycol (PEG)-catalase (1200 U/kg), PEG-SOD (1025 U/kg) (both intravenously administered) or with dimethyl thiourea (DMTU) $(1000 \mathrm{mg} / \mathrm{kg}$ ), or dimethyl sulfoxide (DMSO) (1.5 mg/kg) injected intraperitoneally. Complement and neutrophil (PMN) depletion were accomplished by intraperitoneal injection of CVF (40 U/rat) and rabbit antiserum $(5.0 \mathrm{ml} / \mathrm{kg}$ body weight) against rat neutrophils at 24 and 18 hours, respectively, prior to thermal injury. The Soret Band $(412 \mathrm{~nm})$ was utilized for the quantitative determination of hemolysis. Each bar represents the mean (ISEM) of intravascular hemolysis from five separate animals. Significance ( $p$ value) of each point was derived by comparison with plasma hemoglobin values of unprotected thermally injured rats. $\left({ }^{*} p<0.05,{ }^{* *} p<0.005, * * * p<0.001\right)$. 
Table 1

In vitro hemolysis induced in cobra venom factor (CVF)-treated blood

\begin{tabular}{|c|c|c|c|c|c|}
\hline Blood donor & Treatment of blood & $\begin{array}{l}\not \# \text { of } \\
\text { animals }\end{array}$ & Hemolysis & Significance & $\begin{array}{l}\text { Protection } \\
\text { from } \\
\text { hemolysis }\end{array}$ \\
\hline Normal & None & 4 & $0.79 \pm 0.19$ & -- & - \\
\hline Normal & $\mathrm{CVF}^{*}$ & 6 & $17.93 \pm 0.29$ & $<0.001$ & - \\
\hline Normal & CVF+ catalase $(100 \mathrm{U} / \mathrm{ml})$ & 6 & $6.27 \pm 0.71$ & $<0.001$ & 68.0 \\
\hline Normal & $\mathrm{CVF}+\mathrm{SOD}(100 \mathrm{U} / \mathrm{ml})$ & 7 & $5.73 \pm 0.25$ & $<0.001$ & 71.2 \\
\hline Normal & $\mathrm{CVF}+$ deferoxamine $(0.25 \mathrm{mg} / \mathrm{ml})$ & 6 & $5.35 \pm 0.53$ & $<0.001$ & 73.4 \\
\hline Normal & $\begin{array}{l}\text { CVF + iron saturated deferoxamine } \\
(0.25 \mathrm{mg} / \mathrm{ml})\end{array}$ & 6 & $15.27 \pm 0.78$ & $<0.001$ & 15.2 \\
\hline Complenent-depleted & CVF & 4 & $10.20 \pm 1.79$ & $<0.005$ & 45.1 \\
\hline PMN-depleted & $\mathrm{CVF}$ & 6 & $9.13 \pm 1.21$ & $<0.001$ & 51.3 \\
\hline Normal & $\begin{array}{l}\text { phorbol myristate acetate (PMA) } \\
(200 \mathrm{ng} / \mathrm{ml})\end{array}$ & 4 & $20.8 \pm 1.70$ & $<0.001$ & - \\
\hline
\end{tabular}

* $0.1 \mathrm{U} / 1.0 \mathrm{ml}$ rat blood.

require activation to initiate $\mathrm{RBC}$ lysis. This was demonstrated in vitro by phorbol-stimulated PMN which lysed $75 \%$ of intact RBC [74]. Complement depleted animals when thermally injured also displayed a lack of hemolysis, which is not surprising since complement also functions to activate neutrophils. As previously discussed, the hemolytic process following acute thermal injury could be dramatically attenuated by pre-treatment of animals with SOD, catalase, and hydroxyl radical scavengers. These findings were further substantiated by in vitro studies which demonstrated that catalase and SOD protected red cells from lysis $[30,52,75]$. In efforts to determine if an in vitro model could stimulate the in vivo observations, we added the complement activator, cobra venom factor (CVF), in limited amounts to rat blood. As shown in Table 1, RBC lysis occurred, as revealed by a 23 -fold increase in the absorbance (at $412 \mathrm{~nm}$ ) of plasma after the addition of CVF to whole blood. A reduction (by $68 \%$ ) in hemolysis occurs when catalase $(100 \mathrm{U} / \mathrm{ml}$ blood) was present. A similar reduction in hemolysis was obtained with the presence of an equivalent amount of superoxide dismutase (SOD). The hemolytic event was also susceptible to the presence of the iron chelator deferoxamine $(0.25 \mathrm{mg} / \mathrm{ml})$ in which case there was a $73 \%$ reduction in the amount of hemolysis. The specificity of this protective activity was demonstrated by the loss (by $84.8 \%$ ) of protective effects when iron saturated deferoxamine was used. For comparison, it was demonstrated that an addition of $200 \mathrm{ng}$ of the potent leukocyte activator phorbol myristate acetate (PMA) to normal rat blood $(1.0 \mathrm{ml})$ resulted in hemolysis that was at least as effective as that produced by addition of CVF to rat blood (Table 1). A critical role for the ironbinding protein lactoferrin in oxygen radical-induced hemolysis by neutrophils has also been shown. By employing an antibody against lactoferrin, PMN-mediated RBC cytotoxicity was reduced by greater than $85 \%$ [55].

\section{Summary}

During oxidizing conditions, erythrocyte hemolysis may result from membrane alterations such as the formation of disulfide bonds with integral proteins and the degradation of fatty acids. The presence of anti-oxidant enzymes and radical scavengers during oxidizing conditions largely prevents in vitro red cell lysis. In addition, intravascular hemolysis following thermal trauma is prevented by anti-oxidant therapy and the intervening methods such as granulocyte or complement depletion. Alternately, the requirement of both complement and neutrophils and the protection displayed with SOD, catalase, and hydroxyl radical scavengers indicate that complement-mediated hemolysis may account for a relatively small amount of intravascular hemolysis. This is further supported from our studies with red cells isolated from thermally 
injured rats which [1] failed to demonstrate complement uptake, [2] hemolysis occurred by complement or phorbol ester-stimulated neutrophils, and [3] the hemolytic effect was attenuated in the presence of hydroxyl radical scavengers (DMSO, DMTU), the antioxidant enzymes superoxide dismutase and catalase, and the iron chelator deferoxamine. Additionally, other investigators have demonstrated an important role of iron and lactoferrin in erythrocyte hemolysis by stimulated neutrophils. These observations suggest that thermal injury-induced red cell lysis can be accomplished through activation of neutrophils with the subsequent release of oxygen radicals. Furthermore, complement mediates the neutrophil activation but does not seem to participate directly in the intravascular hemolysis.

\section{Acknowledgement}

The authors wish to thank Pat Ryan for her expert preparation of the manuscript.

Received 5 August 1990; accepted by R. Hess, 12 October 1990

\section{References}

[1] R. B. Johnston, D. E. Lehmeyer and L. A. Guthrie, Generation of superoxide anion and chemiluminescence by human monocytes during phagocytosis and on contact with surface bound immunoglobulin G. J. Exp. Med. 143, 1551-1556 (1976).

[2] J. T. Curutte and B. M. Babior, Biological defense mechanisms: The effect of bacteria and serum on superoxide production by granulocytes. J. Clin. Invest. 53, 1662-1672 (1974).

[3] W. Pick and Y. Keisari, Superoxide anion and hydrogen peroxide production by chemically elicited peritoneal macrophages: Induction by multiple non-phagocytic stimuli. Cell. Immunol. 59, 301-318 (1931).

[4] L. R. DeChatelet, P. S. Shirley and R. B. Johnston, Effect of phorbol myristate acetate on the oxidative metabolism of human polymorphonuclear leukocytes. Blood 47, 545-554 (1976).

[5] R. K. Root and J. A. Metacalf, $\mathrm{H}_{2} \mathrm{O}_{2}$ release from human granulocytes during phagocytosis: Relationship to superoxide anion formation and cellular catabolism of $\mathrm{H}_{2} \mathrm{O}_{2}$ : Studies with normal and cytochalasin B-treated cells. J. Clin. Invest. 60. 1266-1279 (1977).

[6] B. D. Goldstein and O. J. Balchum, Effect of ozone on lipid peroxidation in the red blood cell. Proc. Soc. Exp. Biol. Med. 126, 356 (1967).

[7] E. L. Becker, M. Sigman and J. M. Oliver, Superoxide production induced in rabbit polymorphonuclear leukocytes by synthetic chemotactic peptides and A23187: The nature of the receptor and the requirements of $\mathrm{Ca}^{2+}$. Am. I. Pathol. 95, $81-98$ (1979).
[8] B. M. Baboir, Oxygen-dependent microbial killing by phagocytes. N. Engl. J. Med. 298, $721-725$ (1978).

[9] J. M. McCord, Free radicals and inflammation: Protection of synovial fluid by superoxide dismutase. Science 185, 529-531 (1974).

[10] R. F. del Maestro and I. Alexander, Oxygen derived free radicals: Their role in inflammation. In The inflammatory process. pp. 113-143 (P. Venge, A. Lindbom, Eds.). Almquist and Wiksell International, Stockholm, Sweden 1981 .

[11] S. I. Klebanoff, Oxygen metabolism and the toxic properties of phagocytes. Ann. Intern. Med. 93, 480-490 (1980).

[12] S. J. Klebanoff, Myeloperoxidase-halide-hydrogen peroxide antibacterial system. J. Bacteriol. 95, $2131-3138$ (1968).

[13] A. A. Barber and F. Bernheim, Lipid peroxidation: Its measurement, occurrence and significance in animal tissues. Adv. Geront. Res. 2, 355-404 (1967).

[14] C. J. Dillard and A. L. Tappel, Fluorescent damage products of lipid peroxidation. In Methods in enzymology. Vol. 105 , pp. 337-341 (L. Packer, Ed.). Academic Press, New York 1984.

[15] B. L. Fletcher, C. J. Dillard and A. L. Tappel, Measurement of fluorescent lipid peroxidation products in biological systems and tissues. Anal. Biochem. 52,1-9 (1973).

[16] C. J. Dillard and A. L. Tappel, Fluorescent products have reaction of peroxidizing polyunsaturated fatty acids with phosphatide ethanolamine and phenylalanine. Lipids 8, 183189 (1973).

[17] A. L. Tappel, Measurement of and protection from in vivo lipid peroxidation. In Free radicals in biology. Vol. 4, pp. 1 47 (W. Pryor, Ed.). Academic Press, New York 1980.

[18] E. N. Frankel, Lipid oxidation. Prog. Lipid. Res. 19, 1-22 (1980).

[19] E. W. Kellogg and T. Fridovich, Superoxide, hydrogen peraxide, and singlet oxygen in lipid peroxide by a xanthine oxidase system. J. Biol, Chem, 250, 8812-8817 (1975).

[20] J. M. C. Gutteridge, The protective action of superoxide dismutase on metal catalyzed peroxidation of phospholipids. Biochem. Biophys. Res. Comm. 77, 379-386 (1977).

[21] J. M. McCord, Free radicals and inflammation: Protection of synovial fluid by superoxide dismutase. Science 185, 529-531 (1974).

[22] R. A. Greenwald, Oxygen radicals and connective tissue. J. Rheumatol. 8, 185-187 (1979).

[23] R. A. Greenwald and W. W. May, Inhibition of collagen gelation by action of the superoxide radical. Arth. Rheumatol. 22, 251-259 (1979).

[24] W. S. Lin, D. A. Armstrong and M. Lal, Effects of superoxide dismutase dithiothreital and formate ion on the inactivation of papain by hydroxyl and superoxide radicals in aerated solutions. Int. J. Rad. Biol. 33, 231-243 (1978).

[25] F. Lavelle, A. M. Michelson and L. Dimitnijeur, Biological protection by superoxide dismutase. Biochem. Res. Comm. $55,350-357$ (1973).

[26] D. G. Wickens, T. L. Graff, J. Lunce and T. L. Dormandy, Free radical-mediated aggregation of human gamma globulin. Agents and Actions 11, 650--651 (1981).

[27] H. Carp and A. Janoff, In vitro suppression of serum elastaseinhibitory capacity by reactive oxygen species generated by phagocytosing polymorphonuclear leukocytes. J. Clin. Invest. 63, 793-797 (1978).

[28] R. A. Clark, S. Szat, K. Venkalasubvamanian and E. Schiffman, Chemotactic factor inactivation by myeloperoxidase- 
mediated oxidation of methionine. J. Immunol. 124, 2020 2026 (1980).

[29] S. J. Weiss, Neutrophil-generated hydroxyl radicals destroy RBC targets. Clin. Res. 27, 466A (1979).

[30] S. J. Klebanoff and R. A. Clark, Hemolysis and iodination of erythrocyte components by a myeloperoxidase-mediated system. Blood 45, 699-707 (1975).

[31] E. W. Kellogg and I. Fridovich, Liposome oxidation and erythrocyte lysis by enzymically generated superoxide and hydrogen peroxide. J. Biol. Chem. 252, 6721-6728 (1977).

[32] G. Bartosz, R. Fried, E. Grzelinska and W. Leyko, Effect of hyperoxide radical on bovine-erythrocyte membrane. Eur. J. Biochem. 73, 261-264 (1977).

[33] T. Sachs, C. F. Moldow, P. R. Craddock, J. K. Bowers and $\mathrm{H}$. S. Jacob, Oxygen radical-mediated endothelial cell damage by complement-stimulated granulocytes: An in vitro model of immune vascular damage. J. Clin. Invest. 61, 1161-1167 (1978).

[34] R. H. Simon, C. H. Scroggin and D. Patterson, Hydrogen peroxide causes the fatal injury to human fibroblasts exposure to oxygen radicals. J. Biol. Chem. 256, 7181-7186 (1981).

[35] R. A. Clark and S. J. Klebanoff, Myeloperoxidase-mediated platelet release reaction. I. Clin. Invest. 63, 177-183 (1979).

[36] A. Slivka, A. F. Lobuglio and S. J. Weiss, A potential role for hypochlorous acid in granulocyte-mediated tumor cell cytotoxicity. Blood 52 (2), 347-350 (1980).

[37] R. A. Clark and S. J. Klebanoff, Neutrophil-mediated tumor cell cytotoxicity: Role of the peroxidase system. J. Exp. Med. $141,1442-1447$ (1975).

[38] D. C. Smith and S. J. Klebanoff, $A$ uterine-mediated sperm inhibitory system. Biol. Repro. 3, 229-235 (1970).

[39] B. M. Babior, Oxidizing radicals and red cell destruction. In The function of red bloods cells: Erythrocyte pathobiology. pp. 173-195 (E. F. H. Wallach, Ed.). Alan R. Liss, Inc., New York 1981.

[40] H. S. Jacob and S. E. Lux, Degradation of membrane phospholipids and thiols in peroxide hemolysis: Studies in vitamin E deficiency. Blood 32, 549-568 (1958).

[41] A. Clark and N. H. Hunt, Evidence for reactive oxygen intermediates causing hemolysis and parasite death in malaria. Infect. and Immun. 39, 1-6 (1983).

[42] A. Tomoda, H. Suzuki, Y. Fukuhara, Y. Ueda, K. Niho, Y. Yoneyama and $\mathrm{K}$. Kakinuma, Involvement in active oxygens released by activated leukocytes in hemolytic mechanisms of G6PD deficient red cells. Acta Haematol. Jpn. 47, 189-194 (1981).

[43] W. B. Gratzer, The red cell membrane and its cytoskeleton. J. Biochem. 198, 1-8 (1981).

[44] S. K. Gain and S. B. Shohet, Calcium potentiates the peroxidation of erythrocyte membrane lipids. Biochem. Biophys. Acta. 642, 46-54 (1981).

[45] D. Chiu, B. Lubin and S. B. Shohet, Peroxidative reactions in red cell biology. In Free radicals in biology. Vol. 5, pp. 115160 (W. A. Pryor, Ed.). Academic Press, New York 1982.

[46] W. A. Pryor, Free radical reactions in biological systems. In Free radicals in biology. Vol. IV, pp. 1-47 (W. A. Pryor, Ed.). Academic Press, New York 1976.

[47] A. L. Tappel, The mechanism of oxidation of unsaturated fatty acids catalyzed by hematin compounds. Arch. Biochem. Biophys. 44, 378-395 (1953).

[48] R. W. Carrell, C. C. Winterbourn and E. A. Rachmilewitz, Activated oxygen and hemolysis. Br. J. Haematol. 30, 259264 (1975).
[49] A. Lubin and J. F. Desforges, Effect of Heinz antibodies on red cell deformability. Blood 39, 658-665 (1972).

[50] J. Stocks and T. L. Dormandy, The autoxidation of human red cell lipids induced by hydrogen peroxide. Br. J. Haematol. 20, 95-111 (1971).

[51] C. W. M. Haest, D. Kamp, G. Plasa and B. Dueticke, Intraand intermolecular cross-linking of membrane proteins in intact erythrocytes and ghosts by SH-oxidizing agents. Biochem. Biophys. Acta. 469, 226-230 (1977).

[52] S. J. Weiss, The role of superoxide in the destruction of erythrocyte targets by human neutrophils. J. Biol. Chem. 225, 9912-9917 (1980).

[53] R. E. Lynch and I. Fridovich, Effects of superoxide on the erythrocyte membrane. J. Biol. Chem. 256, 1838-1845 (1978).

[54] H. A. Jacob, Mechanisms of Heinz body formation and attachment to red cell membrane. Sem. Hematol. 7, 341-354 (1970).

[55] G. M. Vercellotti, B. S. van Asbeck and H. S. Jacob, Oxygen radical-induced erythrocyte hemolysis by neutrophils. Critical role of iron and lactoferrin. J. Clin. Invest. 76 (3), 956-962 (1985).

[56] R. A. Rifkind, Heinz body anemia: An ultrastructural study. 11. Red cell sequestration and destruction. Blood 26, 433-448 (1965).

[57] L. T. Chen and L. Weiss, The role of the sinus wall in the passage of erythrocytes through the spleen. Blood 41, 529537 (1973).

[58] H. F. Bunn, B. G. Forget and H. M. Ranney, Human hemoglobins. pp. 282-311. WB Saunders Co., Philadelphia 1977.

[59] L. Kesner, R. J. Kinya and P. C. Chan, Inhibition of erythrocyte membrane $\left(\mathrm{Na}^{+}\right.$and $\left.\mathrm{K}^{+}\right)$-activated ATPase by ozonetreated phospholipids. J. Biol. Chem. 254, 2705 (1979).

[60] B. Roelofsen and L. L. M. van Deenen, Lipid requirement of membrane bound ATPase: Studies on human erythrocyte. Eur. J. Biochem. 40, 245 (1973).

[61] L. M. Snyder, N. L. Fortier, J. Tainor, J. Jacobs, L. Leb, B. Lubin, D. Chin, S. Shohet and N. Mohandas, Effect of hydrogen peroxide exposure on normal human red cell deformability, morphology, surface characteristics, and spectrinhemoglobin cross-linking. J. Clin. Invest. 76, 1971-1977 (1985).

[62] J. R. Hatherill, G. O. Till, L. H. Bruner and P. A. Ward, Thermal injury, intravascular hemolysis, and toxic oxygen products. J. Clin. Invest. $78,629-636$ (1986).

[63] K. S. Chio, V. Reiss, B. Fletcher and A. L. Tappel, Peroxidation of subcellular organelles: Formation of lipofuscin-like fluorescent pigments. Science 166, 1535-1536 (1969).

[64] K. S. Chio and A. L. Tappel, Synthesis and characterization of the fluorescent products derived from malonaldehyde and amino acids. J. Biochem. 8, 2821-2827 (1969).

[65] S. J. Weiss, Neutrophil-mediated methemoglobin formation in the erythrocyte. J. Biol. Chem. 257, 2947-2953 (1982).

[66] D. J. Weiss and J. S. Klausner, Neutrophil-induce erythrocyte injury: A potential cause of erythrocyre destruction in the anemia associate with inflammatory disease. Vet. Pathol. 25 , 450-455 (1988).

[67] H. Robin and J. D. Harley, Factors influencing response of mammalian species to the methemoglobin reduction test. Aust. J. Exp. Biol. Med. Sci. 44, 519-526 (1966).

[68] J. M. Stolk and R. P. Smith, Species differences in methemoglobin reductase activity. Biochem. Pharmacol. 15, $343-351$ (1966). 
[69] G. O. Till, D. C. Beauchamp, D. Menapore, W. Tourtellotte, R. Kunkel, K. J. Johnson and P. A. Ward, Oxygen radicaldependent lung damage following thermal injury of rat skin. J. Trauma. 23, 269-277 (1983).

[70] H. J. Muller-Eberhard, Complement. Ann. Rev. Biochem. 44, 697-724 (1975).

[71] A. F. Esser, Interactions between complement proteins and biological and model membranes. In Biological membranes. Vol. 4, pp. 277-325 (D. Chapman, Ed.). Academic Press, New York 1982.

[72] R. J. Pickering, M. R. Wolfson, R. A. Good and H. Gewurz, Passive hemolysis by serum and cobra venom factor. A new mechanism inducing membrane damage by complement. Proc. Natl. Acad. Sci. USA 62, $521-527$ (1969).
[73] A. Miyama, T. Kato, I. Minoda, T. Uedu and S. Kashiba, Activation of terminal components of human complement by $a$ trypsin-activated complex of human factor $B$ and cobra venom factor. Jpn. J. Microbiol. 20, 507-516 (1976).

[74] S. van Asbeck, J. Hoidal, B. Schwartz, G. Vercellotti, C. Moldow and $\mathrm{H}$. Jacob, Insufflated red cells protect lungs from hyperoxic damage: Role of $R B C$ glutathione in scavenging toxic $\mathrm{O}_{2}$ radicals. Clin. Res. 32, 563A (1984).

[75] J. A. Fee and H. D. Teitlebaum, Evidence that superoxide dismutase plays a role in protecting red blood cells against peroxidative hemolysis. Biochem. Biophys. Res. Comm. 49. 150-158 (1972). 